\title{
A NEW FLUOROSCOPY TECHNIQUE FOR SUPRACONDYLAR HUMERUS FRACTURES
}

\section{UMA NOVA TÉCNICA DE FLUOROSCOPIA PARA FRATURA SUPRACONDILAR DO ÚMERO}

\author{
MIRZA ZAFER DAGTAS ${ }^{1}$ (1), OMer KAYS UNAL ${ }^{1}$ (1) \\ 1. Maltepe University, Orthopedics and Traumatology, Istanbul, Turkey.
}

\section{ABSTRACT}

Introduction: To compare two different intraoperative fluoroscopy techniques used for closed reduction and percutaneous pinning (CRPP) in pediatric patients with supracondylar humerus fractures (SHF). Materials and Methods: Thirty-six patients who underwent SHF surgery from May 2011 to June 2019 were included in the study. During surgery, the classical fluoroscopy method (CFM) was used in 21 patients and the new fluoroscopy method (NFM) was used in the remaining 15 patients. Results: The mean age was $5.14 \pm 1.13$ years in the NFM group and $5.38 \pm 1.36$ years in the CFM group. Mean operative time was $38.14 \pm 5.92$ minutes in the CFM group and $21.54 \pm 3.48$ minutes in the NFM group $(p=0.001)$, while mean fluoroscopy times were $25.65 \pm 3.91$ seconds and $39.84 \pm 7.50$ seconds in the NFM and CFM groups, respectively $(p=0.001)$. The NFM and CFM groups demonstrated similar functional capacity as measured by the Mayo Elbow Score $(p=0.168)$. Direct radiographs obtained to measure Baumann's angle also showed that the two groups had similar results $(p=0.848)$. Conclusions: The NFM is a reliable and successful technique as it leads to shorter operative and fluoroscopy times, as well as providing improvement in functional scores and radiological outcomes in short-term follow-up. Level of Evidence III, Therapeutic Studies-Investigating the Results Level of Treatment.

Keywords: Pediatrics. Humeral fracture. Fluoroscopy.

\section{RESUMO}

Introdução. Visamos comparar duas técnicas de fluoroscopia intraoperatória usadas para redução fechada e fixação percutânea com pino (CRPP) em pacientes pediátricos com fratura supracondilar do úmero (SHF). Materiais e Métodos: Trinta e seis pacientes submetidos à cirurgia de SHF de maio de 2011 a junho de 2019 foram incluídos no estudo. Durante a cirurgia, o método clássico de fluoroscopia (CFM) foi usado em 21 pacientes e o novo método de fluoroscopia (NFM) foi usado nos 15 pacientes restantes. Resultados: A média de idade foi de 5,14 $\pm 1,13$ anos no grupo NFM e 5,38 $\pm 1,36$ anos no grupo CFM. O tempo operatório médio foi de 38,14 $\pm 5,92$ minutos no grupo CFM e 21,54 $\pm 3,48$ minutos no grupo NFM ( $p=$ 0,001 ), enquanto os tempos médios de fluoroscopia foram 25,65 \pm 3,91 segundos e 39,84 $\pm 7,50$ segundos nos grupos NFM e CFM, respectivamente $(p=0,001)$. Os grupos NFM e CFM demonstraram capacidade funcional semelhante medida pelo Mayo Elbow Score $(p=0,168)$. As radiografias diretas obtidas para medir o ângulo de Baumann também mostraram que os dois grupos tiveram resultados semelhantes $(p=0,848)$. Conclusões: O NFM é uma técnica confiável e bem-sucedida, pois reduz o tempo operatório e de fluoroscopia, além de proporcionar melhora nos escores funcionais e resultados radiológicos no acompanhamento de curto prazo. Nível de Evidência III, Estudos terapêuticos - Investigação dos resultados do tratamento.

Palavras-chave: Pediatria. Fratura do úmero. Fluoroscopia.

Citation: Dagtas MZ, Unal OK. A new fluoroscopy technique for supracondylar humerus fractures. Acta Ortop Bras. [online]. 2022;30(1): Page 1 of 4. Available from URL: http://www.scielo.br/aob.

\section{INTRODUCTION}

Supracondylar humerus fracture (SHF) is the most common type of fracture in the elbow region. It has a high frequency in the pediatric age group (3\% of all pediatric fractures), and is especially frequent between 3-7 years of age. ${ }^{1}$ Although the majority of subjects are treated through a non-operative approach (since most present with non-displaced fractures), SHF accounts for the majority of pediatric fractures that require surgical treatment. ${ }^{2}$ Unless treated properly, these fractures may result in severe movement disorders and also deformities in the hand, wrist and forearm, which may have considerable impact on quality of life. ${ }^{3}$ Therefore, appropriate treatment is essential for the prevention of cosmetic and functional morbidities that may occur in the future. ${ }^{4}$

Depending on the mechanism of injury, SHFs are observed as flexion or extension types, with the former being very rare $(<5 \%){ }^{5}$ The common mechanism of injury in extension type SHF is almost always a

All authors declare no potential conflict of interest related to this article.

The study was conducted at Maltepe University, Orthopedics and Traumatology, Istanbul, Turkey. 
fall onto an outstretched hand while the elbow is in extension (forced hyperextension). In recent years, various management concepts have been utilized in pediatric SHFs, including closed or open reduction techniques. Open reduction is associated with a higher incidence of infection and joint stiffness, ${ }^{3,6}$ and since closed reduction can be reliably used in most patients with displaced fractures, the most commonly used method has become the closed reduction and percutaneous pinning (CRPP) with a Kirschner (K) wire method; a method that has been reported as the gold standard. ${ }^{7}$ Although various techniques for CRPP exist, which differ based on the application/number of pins to be used and the opportunity for certain approaches during surgery, it is well-established that all techniques necessitate accurate analysis via fluoroscopy. ${ }^{1}$ It is also important to consider the risk for ulnar nerve injury in up to $10 \%$ of patients depending on the specific approach. ${ }^{8}$ Some surgeons recommend the use of more than $2 \mathrm{~K}$ wires, whereas others support a lateral approach when applying $\mathrm{K}$ wires to protect the ulnar nerve. ${ }^{9}$ During the procedure, fluoroscopy is used to ensure proper reduction. The narrow supracondylar surgery site in children may result in reduction loss, inability to guide the $\mathrm{K}$ wire to the required position, iatrogenic nerve injury, longer operative time and chondral damage. ${ }^{6}$

This study aimed to investigate the differences in operative time between the traditional method and fluoroscopy-guided closed reduction for treating SHFs, regardless of the medial or lateral pinning position used for fixation.

\section{METHODS}

\section{Study population}

All procedures performed in studies involving human participants were in accordance with the ethical standards of the institutional and/or national research committee and with the 1964 Helsinki Declaration and its later amendments or comparable ethical standards. The study was approved by the Clinical Research Ethics Committee of Maltepe University (No:2020/900/32, Date: 03.08.2020). Parents/guardians of all patients included in the study provided informed consent.

Clinical, radiological and functional evaluations were retrospectively performed for 48 patients aged between 1 and 13 who underwent closed reduction followed by fixation with $\mathrm{K}$ wires for the treatment of SHF, from May 2011 to June 2019. Exclusion criteria were as follows: presence of an open fracture or a secondary ipsilateral fracture, being aged younger than 1 or older than 13 years, and having any type of systemic disease or neurovascular injury before the operation. Accordingly, the study included 36 out of 48 patients in total. While all patients underwent SHF fixation with the CRPP method, the classical fluoroscopy method (CFM) was used in 21 patients and the new fluoroscopy method (NFM) was used in the remaining 15 patients. Demographic data, age, operative time, fluoroscopy time, pinning time, time until $\mathrm{K}$ wire removal and complications were assessed in all patients. The Mayo Elbow Score was used for the functional evaluation of the affected elbow. Postoperative follow-up studies included imaging and clinical evaluations. All elbows were examined by a single observer.

\section{Fluoroscopy and surgical procedure}

The patients were placed in the supine position and operated under general anesthesia within the first 24 hours after trauma. 10\% povidone-iodine was used to disinfect the surgical area and then a sterile surgical site was prepared. This was followed by placing the elbows in the fluoroscope to enable imaging. The fluorescent screen was facing the surgeon who performed reduction (across the patient) in order to ensure that the surgeon was able to clearly observe the stages of reduction. Longitudinal traction was maintained while in extension and fluoroscopy was used to avoid varus and valgus positions. The thumb was placed on the olecranon and other fingers on the proximal aspect of the fracture line in order to apply opposite forces while the elbow was in flexion and the forearm was pronated. The final state of reduction was reassessed and the lateral and anteroposterior (AP) radiography images were obtained. The fluoroscope was positioned parallel to the patient in the region of reduction and the humeral long axis was first imaged in the full AP plane. If the reduction was acceptable in the AP plane, the fluoroscope was rotated 90 degrees in order to obtain the lateral view without moving the patient's elbow. After reduction was found to be satisfying in both planes, $2 \mathrm{~K}$ wires of $1.8-2.0 \mathrm{~mm}$ were used for fracture fixation in oblique configuration. The first $\mathrm{K}$ wire was inserted through the lateral condyle and guided towards the proximal medial cortex of the fracture line, and the other $\mathrm{K}$ wire was inserted through the medial condyle and guided beyond the proximal lateral cortex of the fracture line away from the ulnar tunnel. Joint range of motion was evaluated and the surgery was terminated by long arm splinting with the elbow at pronation and 80-90 degrees flexion.

\section{Postoperative follow-up}

During postoperative follow-up, the long arm splint was removed on day 20, after which the passive-active exercises were initiated. The $\mathrm{K}$ wires were scheduled for removal between the $4^{\text {th }}$ and $6^{\text {th }}$ postoperative weeks, when periosteal callus formation was observed and the fracture line was blurred. It was deemed necessary to keep the $\mathrm{K}$ wire in place for one or two more weeks in cases where callus formation around the fracture line was not sufficient. The final follow-up visit which included functional assessment was performed on postoperative day 90.

\section{Radiological evaluation}

Radiological evaluation was performed on postoperative days 1, 15 and 30 from the AP and lateral elbow radiographs of the operated side in all patients. Findings related to union at the fracture line were confirmed with radiological evaluations during follow-up. The radiological evaluation was finalized by measuring the Baumann's angle on AP elbow radiographs of both the affected and contralateral sides (for the purpose of comparison) during the final follow-up visit on day 90.

\section{Statistical analysis}

All data was analyzed with SPSS v25. Normality check was performed with the Shapiro Wilk test. Continuous variables were expressed as mean \pm standard deviation. The Student t-test was used to compare the means. Chi square tests were used for the comparison of the distribution of categorical variables. Statistical significance was accepted as $p<0.05$.

\section{RESULTS}

The study included 36 patients who underwent CRPP and met the inclusion criteria. Mean age was $5.26 \pm 1.24$ (range, 1-13) years, $58 \%$ (21) were male and $42 \%$ (15) were female. The mean ages of the patients included in the NFM and CFM groups were $5.14 \pm$ 1.13 and $5.38 \pm 1.36$ years, respectively (Table 1 ).

Mean operative time was $38.14 \pm 5.92$ minutes in the CFM group and $21.54 \pm 3.48$ minutes in the NFM group $(p=0.001)$. The mean fluoroscopy times were $39.84 \pm 7.50$ seconds and $25.65 \pm 3.91$ seconds in the CFM and NFM groups, respectively ( $p=0.001$ ). There was no significant difference between the CFM and NFM groups in terms of Mayo Elbow Score ( $p=0.168)$.

Direct radiographs obtained on postoperative day 90 showed that there was no significant difference between the two groups in terms of Baumann's angle $(p=0.848)$. When the operated and contralateral 
sides of patients were compared, there was again no significant difference in Baumann's angle values in either group ( $p=0.972)$. The time until pin removal of the NFM group (31.14 \pm 4.19 days) was significantly shorter compared to the CFM group (34.71 \pm 4.42 days) $(p=0.020)$. The time until removal of $K$ wires was 38.74 \pm 4.45 days in the NFM group and $42.05 \pm 4.71$ days in the CFM group, demonstrating a significantly shorter duration with the use of NFM ( $p=0.040$ ) (Table 2). No complications were recorded in any of the patients included in the study.

Table 1. The age and gender distribution of the patients.

\begin{tabular}{c|c|c|c}
\hline & $\begin{array}{c}\text { New Method } \\
(\mathbf{n = 1 5})\end{array}$ & $\begin{array}{c}\text { Classical Method } \\
(\mathbf{n}=\mathbf{2 1})\end{array}$ & P value \\
\hline Age & $5,14 \pm 1,13$ & $5,38 \pm 1,36$ & 0,568 \\
\hline Gender & & & \\
\hline Male & $9(60.0 \%)$ & $12(57.1 \%)$ & \multirow{2}{*}{0.864} \\
\hline Female & $6(40.0 \%)$ & $9(42.9 \%)$ & \\
\hline
\end{tabular}

Table 2. The comparison of surgical features and outcomes.

\begin{tabular}{c|c|c|c}
\hline & $\begin{array}{c}\text { New Method } \\
(n=15)\end{array}$ & $\begin{array}{c}\text { Classical } \\
\text { Method } \\
(\mathrm{n}=21)\end{array}$ & P value \\
\hline Operation time (minutes) & $21,54 \pm 3,48$ & $38,14 \pm 5,92$ & 0.001 \\
\hline Scopy time (seconds) & $25,65 \pm 3,91$ & $39,84 \pm 7,50$ & 0.001 \\
\hline Mayo Elbow Score & $82,34 \pm 10,15$ & $77,62 \pm 9,70$ & 0.168 \\
\hline Bauman angle (90 day) & $71,27 \pm 2,69$ & $71,57 \pm 5,65$ & 0.848 \\
\hline Bauman Angle (contralateral elbow) & $76,67 \pm 2,32$ & $76,90 \pm 2,23$ & 0.758 \\
\hline Difference of Bauman Angle & 5.404 .34 & $5.33 \quad 6.41$ & 0.972 \\
\hline Fracture reduction time (days) & $31,14 \pm 4,19$ & $34,71 \pm 4,42$ & 0.020 \\
\hline Removal of K-wire (days) & $38,74 \pm 4,45$ & $42,05 \pm 4,71$ & 0.040 \\
\hline & \multicolumn{3}{|l}{}
\end{tabular}

\section{DISCUSSION}

The most important finding obtained in this study was that the use of a new method for fluoroscopy in CRPP led to a significant reduction in operative time and intraoperative fluoroscopy time as compared to the classical method of fluoroscopy.

It has been reported that around $16 \%$ of SHF fractures in children require surgical treatment. ${ }^{10}$ The main goal of treatment is to re-establish normal elbow structure/function and to prevent neurovascular complications, while also ensuring normal cosmetic appearance of the elbow. ${ }^{11}$ Prolonged operative time leads to a higher risk of reduction loss and complications. Therefore, completing the surgery successfully also depends on intraoperative time, making procedure duration a factor of interest in the surgical treatment of SHF.12 In a study by Naik et al., mean operative times were reported to be 28.3 \pm 1.6 and $30 \pm 3.6$ minutes with two different CRPP techniques. ${ }^{13}$ Striano et al. reported mean operative times ranging from 20.4 minutes to 46.6 minutes in patients undergoing CRPP for different types of fractures. ${ }^{14}$ In the present study, the utilization of NFM for intraoperative evaluation led to a significantly shorter operative time compared to CFM, as well as in comparison to the majority of results reported in the literature, regardless of surgical technique.

In a study by Kraus et al., different methods used in the surgical treatment of SHF were compared in terms of intraoperative fluoroscopy exposure and it was underlined that proper selection of surgical technique was essential to avoid unnecessary fluoroscopy exposure (for the surgical team, patient and other medical staff), and that surgeons should not insist on inappropriate surgical techniques which prolonged intraoperative fluoroscopy time. ${ }^{15}$ In another study, Eismann et al. demonstrated that fluoroscopy time was highly variable during the CRPP procedures performed for SHFs, and the operative time was also prolonged depending on $\mathrm{C}$-arm orientation (standard and inverted). ${ }^{16}$ In the present study, the NFM led to a significantly shorter fluoroscopy time as compared to the CFM, which would provide considerably lower radiation exposure and protect the wellbeing of the surgeon, patient and other medical staff.

According to the literature, the results were significantly improved in patients who were evaluated with the Mayo Elbow Score following CRPP performed for SHF.17 Although we observed somewhat better Mayo Elbow Scores in the NFM group compared to the CFM group, statistical significance was not present ( $p=0.168$ ). Nevertheless, we attributed the beneficial change to accelerated recovery and shorter operative time resulting from the use of NFM. Considering the lack of significance and the limited number of individuals in this study, it is evident that further studies must be performed to elucidate whether alterations in the conduct of fluoroscopy benefit surgical duration and outcomes.

In a study by Mehlman et al., two different fluoroscopy methods were used in 115 patients with SHF who underwent surgery with the CRPP method. Postoperative radiological evaluation showed that the Baumann's angle was within the normal range in $83 \%$ of the patients and that functional results were also satisfactory. ${ }^{18}$ According to another study by Li et al. which compared the conventional fluoroscopy and mini-fluoroscopy systems in patients undergoing CRPP for SHF, mini-fluoroscopy guidance employed during surgery led to prolonged operative and fluoroscopy times and an increase in the number of fluoroscopy procedures -with the added fact that Baumann's angles were similar in the two methods. ${ }^{19}$ In the present study, both of the fluoroscopy methods led to an improvement in Baumann's angle without any significant superiority to one another, which is similar to the results provided in the literature. Evidence from prior research on SHF dictates that the removal of $K$ wires following CRPP should be performed during the $3^{\text {rd }}$ to $4^{\text {th }}$ postoperative weeks. ${ }^{20}$ However, it is also known that some surgeons do not remove the $\mathrm{K}$ wires until weeks 4,5 or $6 .{ }^{21}$ This can be attributed to the fact that surgeons generally prefer to remove $\mathrm{K}$ wires when they feel it is safe to do so, instead of considering radiographic evidence of fracture healing as the primary factor. Bearing in mind the possible bias caused by this approach, the time until removal of $\mathrm{K}$ wires was slightly longer in the NFM group as compared to the literature, but it was also shorter than the removal time in the CFM group. Although this may indicate another advantage, it is also possible that this was caused by confirmation bias in favor of the new method. We also believe that the mentioned time will come closer to the values reported in the literature as we expand our experience.

The limitations of this study were as follows: limited number of patients, the fact that the standard surgical method (lateral or cross-pinning) was not preferred for CRPP and that Flynn's criteria, which are frequently employed in the literature, were not used to evaluate functional recovery.

\section{CONCLUSION}

Among the fluoroscopy methods used during CRPP performed for $\mathrm{SHF}$, the NFM, as we described here, appears to have successful outcomes in the short-term. The NFM is a reliable technique especially since it provides shorter operative time and fluoroscopy time, while also increasing functional scores and improving radiological outcomes.

AUTHORS' CONTRIBUTION: Each author contributed individually and significantly to the development of this article. MZD: conception and design of the study, data acquisition, analysis and interpretation, drafting the article and approval of the final version; OKU: conception and design of the study, drafting the article, revising it critically for important intellectual content and approval of the final version. 


\section{REFERENCES}

1. Otsuka NY, Kasser JR. Supracondylar Fractures of the Humerus in Children. J Am Acad Orthop Surg. 1997;5(1):19-26.

2. Shrader MW. Pediatric supracondylar fractures and pediatric physeal elbow fractures. Orthop Clin North Am. 2008;39(2):163-71.

3. Vaquero-Picado A, González-Morán G, Moraleda L. Management of supracondylar fractures of the humerus in children. EFORT Open Rev. 2018;3(10):526-40.

4. Tuomilehto N, Sommarhem A, Nietosvaara AY. 9 years' follow-up of 168 pin-fixed supracondylar humerus fractures in children. Acta Orthop. 2018;89(3):351-6.

5. Roberts L, Strelzow J, Schaeffer EK, Reilly CW, Mulpuri K. Nonoperative Treatment of Type IIA Supracondylar Humerus Fractures: Comparing 2 Modalities. J Pediatr Orthop. 2018;38(10):521-6.

6. Del Valle-Hernández E, Marrero-Barrera PA, Beaton D, Bravo D, Santiago S, Guzmán-Pérez H, et al. Complications associated with Pediatric Supracondylar Humeral Fractures. P R Health Sci J. 2017;36(1):37-40.

7. Carvalho RA, Filho NF, Neto AB, Reis GD, Dias MP. Supracondylar fracture of the humerus in children: fixation with two crossed kirschner wires. Rev Bras Ortop. 2012;47(6):705-9.

8. Lee SS, Mahar AT, Miesen D, Newton PO. Displaced pediatric supracondylar humerus fractures: biomechanical analysis of percutaneous pinning techniques. J Pediatr Orthop. 2002;22(4):440-3.

9. Tuomilehto N, Kivisaari R, Sommarhem A, Nietosvaara AY. Outcome after pin fixation of supracondylar humerus fractures in children: postoperative radiographic examinations are unnecessary. Acta Orthop. 2017;88(1):109-15.

10. Holt JB, Glass NA, Shah AS. Understanding the Epidemiology of Pediatric Supracondylar Humeral Fractures in the United States: Identifying Opportunities for Intervention. J Pediatr Orthop. 2018;38(5):e245-e51.

11. Li M, Xu J, Hu T, Zhang M, Li F. Surgical management of Gartland type III supracondylar humerus fractures in older children: a retrospective study. $J$ Pediatr Orthop B. 2019;28(6):530-5.
12. Liu RW, Roocroft J, Bastrom T, Yaszay B. Surgeon learning curve for pediatric supracondylar humerus fractures. J Pediatr Orthop. 2011;31(8):818-24.

13. Naik LG, Sharma GM, Badgire KS, Qureshi F, Waghchoure C, Jain V. Cross Pinning Versus Lateral Pinning in the Management of Type III Supracondylar Humerus Fractures in Children. J Clin Diagn Res. 2017;11(8):Rc01-rc3.

14. Striano BM, Brusalis CM, Flynn JM, Talwar D, Shah AS. Operative Time and Cost Vary by Surgeon: An Analysis of Supracondylar Humerus Fractures in Children. Orthopedics. 2019;42(3):e317-e21.

15. Kraus R, Joeris A, Castellani C, Weinberg A, Slongo T, Schnettler R. Intraoperative radiation exposure in displaced supracondylar humeral fractures: a comparison of surgical methods. J Pediatr Orthop B. 2007;16(1):44-7.

16. Eismann EA, Wall EJ, Thomas EC, Little MA. Direct beam radiation exposure to surgeons during pinning of supracondylar humerus fractures: does C-arm position and the attending surgeon matter? J Pediatr Orthop. 2014;34(2):166-71.

17. Moraleda L, Valencia M, Barco R, González-Moran G. Natural history of unreduced Gartland type-II supracondylar fractures of the humerus in children: a two to thirteen-year follow-up study. J Bone Joint Surg Am. 2013;95(1):28-34.

18. Mehlman C, Crawford A, Mcmillion T, Roy D. Operative treatment of supracondylar fractures of the humerus in children: the Cincinnati experience. Acta Orthop Belg. 1996;62:41.

19. Li ZX, Wong KPL, Wong JLY, Lim KBL, Mahadev A. The utility of mini C-arm in the fixation of unstable paediatric supracondylar humeral fractures. Injury. 2019;50(11):1992-6.

20. Acosta AM, Li Y-J, Bompadre V, Mortimer A, Trask M, Steinman SE. The Utility of the Early Postoperative Follow-up and Radiographs After Operative Treatment of Supracondylar Humerus Fractures in Children. Journal of Pediatric Orthopaedics. 2020;40(5):218-22.

21. lobst CA, Stillwagon M, Ryan D, Shirley E, Frick SL. Assessing Quality and Safety in Pediatric Supracondylar Humerus Fracture Care. J Pediatr Orthop. 2017;37(5):e303-e7. 